\section{The Authors Respond:}

In response to our study, ${ }^{1}$ Stewart describes several methodological limitations that are inherent in retrospective study designs. Although many of these limitations were addressed in our original article, some warrant further discussion. Stewart is concerned that our relatively small sample size could possibly lead to a Type II error. Although it would have been feasible to increase our sample size by including multiple respiratory syncytial virus (RSV) seasons, we chose to limit our study to 1 RSV season due to subsequent changes in the American Academy of Pediatrics (AAP) guidelines for palivizumab ${ }^{2}$ as well as our health plan's prior authorization policy. Accordingly, the compliance patterns observed in our cohort correspond to the specific policies in place during the RSV season under study.

Stewart made errors in his interpretation of our data. As Stewart points out, the retrospective nature of administrative claims data does inherently limit the ability to control for treatment indication. Nonetheless, the difference in RSV-related outpatient visits highlighted by Stewart was not found to be statistically significant between the 2 groups. Stewart also points out the differences in length of patient follow-up as a potential influence on cost data. Because we reported all cost data on a per member per month (PMPM) basis, the differences in length of membership were thereby controlled.

Additionally, our assumption that the first dose of palivizumab was given in the neonatal intensive care unit (NICU) was appropriate and necessary as part of conducting research with administrative claims data. As a health plan we often do not have access to medical claims until months after the date of service. And, we do not have the claim level detail on inpatient visits to know whether or not a specific dose of a specific medication was given. As a result, compliance for our study could take into consideration only outpatient doses.

Finally, our comments questioning the cost-effectiveness of palivizumab prophylaxis were based on the finding that compliant infants continued to have RSV-related outpatient visits. We feel that this is an important issue that warrants further investigation considering the need to control rising costs in today's health care environment. Only by raising these issues and performing the appropriate studies can we properly develop the strategies, such as prior authorization, utilized by managed care organizations to identify the most appropriate patient populations for high-cost drugs.

Jocelyn L. Hain (Diehl), PharmD
Clinical Pharmacy Specialist
diehlj@upmc.edu
University of Pittsburgh Medical Center (UPMC) Health Plan

Jessica R. Daw, PharmD

Manager, Clinical Pharmacy

University of Pittsburgh Medical Center (UPMC) Health Plan
Kim C. Coley, PharmD

Professor of Pharmacy and Therapeutics

University of Pittsburgh School of Pharmacy

\section{Renee Rayburg, RPh}

Director, Clinical Services

BioScrip, Inc.

\section{DISCLOSURES}

The authors report no conflicts of interest related to the subjects or products discussed in this response.

\section{REFERENCES}

1. Diehl JL, Daw JR, Coley KC, Rayburg R. Medical utilization associated with palivizumab compliance in a commercial and managed Medicaid health plan. J Manag Care Pharm. 2010;16(1):23-31. Available at: http://www. amcp.org/data/jmcp/23-31.pdf.

2. American Academy of Pediatrics, Committee on Infectious Diseases. From the American Academy of Pediatrics: Policy statements-Modified recommendations for use of palivizumab for prevention of respiratory syncytial virus infections. Pediatrics. 2009;124(6):1694-701. Available at: http://pediatrics.aappublications.org/cgi/reprint/124/6/1694. Accessed August 10, 2010.

\section{The Editors Respond:}

Stewart predictably advocates for unrestricted use of palivizumab in response to our publication of 2 articles that described evaluation of clinical and cost outcomes associated with quality improvement initiatives in 2 unrelated managed care organizations. It is worth noting that the utilization management program described by Buckley et al. ${ }^{1}$ was developed in a health system that is celebrated for its commitment to continuous quality improvement ${ }^{2}$ and has been ranked consistently in the top 5 integrated health systems each year for the last decade. ${ }^{3}$ Second, this utilization management program was based on the best evidence as evaluated by infectious disease experts writing for the American Academy of Pediatrics (AAP) in $2006^{4}$ and was developed by clinicians in this integrated health system who have a focus on quality improvement including the elimination of waste. The results of evaluation of this intervention involving a prior authorization (PA) requirement for coverage of palivizumab include palivizumab drug cost savings of more than $\$ 2.4$ million over 3 years without evidence of adverse clinical outcomes. Although preliminary because of its exploratory and descriptive design, this study by Buckley et al. is good news for health plans, including the 85 health plans that ranked prevention of respiratory syncytial virus (RSV) infection as the fourth highest-priority therapy category for utilization management of specialty pharmaceuticals in 2009, and the $10 \%$ of these health plans that reported "recently" adding a PA for palivizumab for RSV in 2009.5

Stewart complains of "confounding by indication." We agree that the treated group in Buckley et al. met the PA criteria based on the AAP guideline. Therefore, the treated group 
should be sicker, and we note that the PA process was intended to produce that very outcome (i.e., target palivizumab therapy to children most likely to benefit from it). Buckley et al. also pointed out in their study report that the PA-denied group was healthier. The assertion of confounding by indication, although theoretically correct in any observational comparison of treatment approaches, is a red herring in this instance. Buckley et al. did not study the efficacy of palivizumab (i.e., treatment versus nontreatment) in at-risk infants; clinical trials have already shown that palivizumab is efficacious in this group. Instead, Buckley et al. described the outcomes of a PA process that targeted the use of palivizumab to at-risk infants (as opposed to infants who did not meet the AAP criteria for risk). Importantly, the developers of this clinically sound PA intervention did not advocate nontreatment of at-risk infants; they advocated targeting treatment to only at-risk infants.

Stewart also criticizes the study report by Buckley et al. as "improperly designed to determine the appropriateness of the PA process," which apparently represents criticism of the AAP and its infectious disease experts who created the policy statement and recommendations for the use of palivizumab for the prevention of RSV infections. ${ }^{4}$ These infectious disease experts were apparently mindful of the high cost of palivizumab and the inconsistency in the medical literature regarding the factors that reliably predict risk of RSV-related hospitalization, because the 2009 update was more definitive than the previous AAP guidance (2006) in specifying the groups of infants who are not likely to benefit from immunoprophylaxis with palivizumab. ${ }^{6}$

Stewart cites the RSV hospitalization rate of $4.0 \%$ for the PA-denied group in Buckley et al. as evidence of lack of costeffectiveness for the PA process, apparently suggesting that some or all of the hospitalizations in the PA-denied group could have been prevented had physicians in this health plan's network been given "free rein" to prescribe palivizumab regardless of AAP criteria. This is speculation because no study has assessed the efficacy of palivizumab in infants not at high risk. However, the speculation appears to be partially contravened by evidence of RSV hospitalization rates in palivizumabtreated patients: $4.8 \%$ in the IMpact-RSV clinical trial ${ }^{7}$ that was the basis for U.S. Food and Drug Administration (FDA) approval of palivizumab for the prevention of serious lower respiratory tract disease caused by RSV in pediatric patients at high risk of RSV disease ${ }^{8}$ 6.4\% in the PA-approved group in Buckley et al.'s study; and $1.3 \%$ in the Palivizumab Outcomes Registry study, a prospective observational study of palivizumab-treated patients in routine clinical practice. ${ }^{9}$ The range of RSV hospitalization rates is notably wide. As Buckley et al. suggested in their study report, making comparisons to previous work is difficult because of differences among studies. The Registry study was not limited to infants meeting AAP criteria and defined RSV hospitalizations as stays of 24 hours or more in which "RSV infection was confirmed by virology testing."
Despite the criticism from Stewart of the report by Buckley et al. and of the report by Diehl et al. regarding outcomes associated with compliance versus noncompliance with palivizumab dosing,$^{10}$ these 2 reports include findings that comport with those of previous research. As we noted in our assessment of the available evidence on the subject, data regarding the relationship between palivizumab compliance and outcomes in routine clinical practice are mixed. ${ }^{11}$ In the Palivizumab Outcomes Registry study, investigators found no significant association between RSV-related hospitalization and compliance defined as receipt of the number of expected palivizumab injections regardless of timing; however, when compliance was defined as the receipt of each dose within 35 days of the previous dose in patients with at least 2 doses, the compliant group had a $0.5 \%$ lower rate of RSV-related hospitalization (1.2\% vs. $1.7 \%, P=0.007){ }^{9}$ By this measure, "moving the needle" from noncompliance to compliance in 200 palivizumab-treated infants would prevent 1 RSV-related hospitalization. Using a more stringent definition of compliance and a small sample limited to infants meeting the health plan's PA criteria, Diehl et al. found a $1.2 \%$ rate of RSV-related hospitalization among at-risk infants who received palivizumab but were noncompliant. ${ }^{10}$ Given the mixed and limited evidence available to date, the high cost of palivizumab, and the potentially serious consequences of noncompliance for at-risk infants, we hope that future research will examine more closely the association of the timing of palivizumab dosing with rates and costs of RSV hospitalizations and other negative clinical outcomes (e.g., use of intensive care units or ventilators). These analyses are relatively simple to perform using administrative claims data, and we encourage health plans to do so.

In summary, we observe that (a) the PA-denied group in Buckley et al. did not meet best evidence criteria for use of palivizumab; (b) RSV hospitalizations occurred in the clinical trials and in the Palivizumab Outcomes Registry among patients who received palivizumab prophylaxis; (c) the cumulative data suggest that there is a small but clinically important difference in RSV hospitalization for patients compliant with palvizumab dosing versus those noncompliant; and (d) health plans are expected to endorse and promote evidence-based practice. We defer to the infectious disease experts and the AAP 2009 policy statement for unequivocal answers to Stewart's other criticisms of the use of evidence in clinical practice.

\section{Frederic R. Curtiss, PhD, RPh, CEBS}

Editor-in-Chief

Journal of Managed Care Pharmacy

fcurtiss@amcp.org

Kathleen A. Fairman, MA

Associate Editor and Senior Methodology Reviewer

Journal of Managed Care Pharmacy 


\section{DISCLOSURES}

The authors report no conflicts of interest related to the subjects or products discussed in this response.

\section{REFERENCES}

1. Buckley BC, Roylance D, Mitchell MP, Patel SM, Cannon HE, Dunn JD. Description of the outcomes of prior authorization of palivizumab for prevention of respiratory syncytial virus infection in a managed care organization. J Manag Care Pharm. 2010;16(1):15-22. Available at: http://www.amcp. org/data/jmcp/15-22.pdf.

2. Leonhardt D. Making health care better. NY Times. November 3, 2009. Available at: http://www.nytimes.com/2009/11/08/magazine/08Healthcare-t. html?_r=2\&th\&emc=th. Accessed August 13, 2010.

3. Carlson J. Integrating success - top performing health networks offer lessons in using efficiencies, expertise to improve health care. Mod Healthc. 2010;40(4):28-31.

4. Subcommittee on Diagnosis and Management of Bronchiolitis. Clinical practice guideline. Diagnosis and management of bronchiolitis. Pediatrics. 2006;118(4):1774-93. Available at: http://pediatrics.aappublications.org/cgi/ reprint/118/4/1774. Accessed August 14, 2010.

5. EMD Serono Specialty Digest, 6th edition. Managed care strategies for specialty pharmaceuticals. Available at: http://specialtydigest.emdserono. com/. Accessed August 14, 2010.
6. Committee on Infectious Diseases. Policy statement-modified recommendations for use of palivizumab for prevention of respiratory syncytial virus infections. Pediatrics. 2009;124(6):1-8. Available at: http://pediatricsaappublications.org/cgi/reprint/peds.2009-2345vl. Accessed August 14, 2010

7. The IMpact-RSV Study Group. Palivizumab, a humanized respiratory syncytial virus monoclonal antibody, reduces hospitalization from respiratory syncytial virus infection in high-risk infants. Pediatrics. 1998;102(3):531-37.

8. U.S. Food and Drug Administration. Product label. Synagis (palivizumab) for intramuscular administration. December 2, 1999. Available at: http:// www.accessdata.fda.gov/drugsatfda_docs/label/2002/palimed102302LB.pdf. Accessed August 14, 2010.

9. Frogel M, Nerwen C, Cohen A, VanVeldhuisen P, Harrington M, Boron M. Prevention of hospitalization due to respiratory syncytial virus: results from the Palivizumab Outcomes Registry. J Perinatol. 2008;28(7):511-17.

10. Diehl JL, Daw JR, Coley KC, Rayburg R. Medical utilization associated with palivizumab compliance in a commercial and managed Medicaid health plan. J Manag Care Pharm. 2010;16(1):23-31. Available at: http://www. amcp.org/data/jmcp/23-31.pdf.

11. Curtiss FR, Fairman KA. Utilization management opportunities for palivizumab for prophylaxis of respiratory syncytial virus complications in infants. J Manag Care Pharm. 2010;16(1):59-66. Available at: http://www. amcp.org/data/jmcp/59-66.pdf.

Editors' note to online readers: All JMCP articles contain hyperlinks to the source documents for free-access references. These hyperlinks are embedded in the reference numbers cited in the text as well as in the list of references at the end of each article. 